\title{
Cardiovascular Risk Factors among Outpatients: An Alarming Sign of the Epidemiological Transition in Developing Country?
}

\section{Modibo Coulibaly ${ }^{1}$ (D), Dramane Samaké2 ${ }^{2}$, Sonfo Boubacar ${ }^{3}$, Lamine Sidibé ${ }^{2}$, Moussa Diawara ${ }^{1}$, Mamoudou Barry1, Valentin Sagara1, Bréhima Traoré4, Oumar Guindo4, Bakary Maiga5, Amagana Dolo ${ }^{6}$}

\author{
${ }^{1}$ Department of Biomedical Laboratory, Hospital of Mopti, Mopti, Mali \\ ${ }^{2}$ Department of Medicine, Hospital of Mopti, Mopti, Mali \\ ${ }^{3}$ Department of Cardiology, Teaching Hospital of Kati, Bamako, Mali \\ ${ }^{4}$ Department of Public Health, Hospital of Mopti, Mopti, Mali \\ ${ }^{5}$ Faculty of Medicine and Odonto Stomatology, University of Science Technical and Technologies de Bamako, Bamako, Mali \\ ${ }^{6}$ Faculty of Pharmacy, University of Science Technical and Technologies de Bamako, Bamako, Mali \\ Email: modibocoulibaly@yahoo.com
}

How to cite this paper: Coulibaly, M., Samaké, D., Boubacar, S., Sidibé, L., Diawara, M., Barry, M., Sagara, V., Traoré, B., Guindo, O., Maiga, B. and Dolo, A. (2021) Cardiovascular Risk Factors among Outpatients: An Alarming Sign of the Epidemiological Transition in Developing Country? World Journal of Cardiovascular Diseases, 11, 181-194.

https://doi.org/10.4236/wjcd.2021.113019

Received: January 23, 2021

Accepted: March 20, 2021

Published: March 23, 2021

Copyright ( 2021 by author(s) and Scientific Research Publishing Inc. This work is licensed under the Creative Commons Attribution International License (CC BY 4.0).

http://creativecommons.org/licenses/by/4.0/ (c) (i) Open Access

\begin{abstract}
Background: Noncommunicable diseases are the leading cause of death in the world and low and middle-income countries suffer from preventable premature death. The aim of this study was to assess the risk factors for noncommunicable disease (NCDs) in general and particular cardiovascular diseases (CVDs) among the outpatients of our department of medicine. Methods: We performed a cross-sectional study from April to December 2017 by the consecutive enrollment of outpatients who attended in our department of medicine of Hôpital Sominé DOLO de Mopti, Mali. Clinical and laboratory data were measured for cardiovascular risk assessment. Framingham Risk Score (FRS) and Systemic Coronary Risk Estimation (SCORES) were computed by using Framingham and SCORE equations. Metabolic syndrome was defined using the harmonized criteria from the International Diabetes Federation (IDF) and the American Heart Association/National Heart, Lung, and Blood Institute (AHA/NHLBI). Data were captured in excel and analyzed with $R$ version 4.0.3. The statistical significance was set at $p=0.05$. Results: A total of 292 patients were enrolled in this study. The prevalence of traditional cardiovascular risk factors was $36.64 \%, 21.57 \%, 14.04 \%$, and $13.01 \%$ for high blood pressure, hyperglycemia, smoking, and alcohol consumption, respectively. The metabolic syndrome accounted for $23.63 \%$. The mean body mass
\end{abstract}


index was $26.10 \pm 7 \mathrm{~kg} / \mathrm{m}^{2}$. The overall 10 -year risk for cardiovascular events or death was $26.3 \%$ and $8.6 \%$ according to the FRS and SCORE equation, respectively. The 10-year risk of cardiovascular events according to the FRS was significantly higher in subjects aged 50 and above compared to subjects aged under 50 years, $34.46 \%$ vs $13.16 \%, \mathrm{p}<0.001$. Likewise, the 10 -year risk for cardiovascular death according to SCORE equation was also significantly higher in subjects aged 50 and above compared to subjects under 50 years, $9.43 \%$ vs $2.09 \%, \mathrm{p}=0.02$. Regarding gender, the FRS was significantly higher in men compared to women $49.50 \%$ vs $7.84 \%, \mathrm{p}<0.001$. This same trend was observed with the SCORE, $14.67 \%$ vs $4.13 \%, p=0.03$. Conclusion: Our data corroborate the increasing prevalence of cardiovascular risk factors in SSA. A comprehensive cardiovascular risk factors assessment should be implemented in all stages of health facilities and a longitudinal follow-up could help shed a light on the epidemiology of NCDs in general and particularly CVDs and thereby improve their control policies in SSA.

\section{Keywords}

Cardiovascular Risk Factors, Framingham Risk Score, SCORE, Metabolic Syndrome

\section{Introduction}

Non-communicable diseases (NCDs) are the leading cause of death in the world. It accounts for $71 \%$ of the 57 million global deaths. According to the World Health Organization (WHO), every year 16 million people die prematurely between 30 and 69 years of age due to NCDs. In 2016, 78\% of all NCDs deaths, and $85 \%$ of premature adult NCDs deaths, occurred in low-and middle-income countries (LMICs) which are characterized by poor health systems and less trained or insufficient partitioners. In Mali, NCDs deaths account for 30\% of all causes of death, among these cardiovascular death represented $12 \%$ [1]. In the face of this alarming global situation, the WHO estimates that if nothing changes in the LMICs, the burden attributable to NCDs would be the US $\$ 11.2$ billion per year by 2025 far beyond the financial capacity of the health systems of these countries. Given that more than $80 \%$ of these premature deaths due to CVD are related to modifiable risk factors [1] and in order to reduce NCDs burden, a number of prevention strategies are taking place. However, a good knowledge of the epidemiology of risk factors is necessary for the informed policies making process. There are some tools that allow estimating the 10-risk of cardiovascular events (fatal or non-fatal coronary artery disease, stroke, peripheral vascular disease, chronic heart failure, heart death), this is the case of the American model Framingham 8 Risk Score (FRS) equation [2] [3]. The European cardiovascular risk assessment tool named Systemic COronary Risk Estimation (SCORE) equation estimates a 10-year risk of cardiovascular death [4] [5]. Metabolic syndrome (MetS) is a cluster of risk factors associated with cardiovascular diseases and diabetes 
type 2. There are different definitions and criteria for MetS. The first came from WHO, 1998 [6], the second criteria came from the National Cholesterol Education Program Adult Treatment Panel III (NCEP-ATP III) [7] in 2001 and the third criteria came from the International Diabetes Federation (IDF) and the American Heart Association/National Heart, Lung, and Blood Institute (AHA/ NHLBI) [8]. The AHA/NHLBI slightly modified the NCEP-ATP III criteria but did not mandate abdominal obesity as a required risk factor. According to the AHA/NHLBI recommendation, the cut points of the threshold for waist circumference to define abdominal obesity in people of European origin (Europids) should be $\geq 102$ and $\geq 88 \mathrm{~cm}$, for men and women, respectively. The remaining 4 risk factors elevated triglyceride (TG), reduced high-density lipoprotein cholesterol (HDL-C), elevated blood pressure, and elevated fasting glucose was similar in definition to those of the IDF [9]. The purpose of this study was to assess cardiovascular risk factors and epidemiological characteristics among outpatients through a comprehensive assessment of in the department of Medicine of Mopti Hospital (HSD-M).

\section{Material and Methods}

The study was conducted at the department of medicine of HSD-M where outpatients attended. We performed a cross-sectional study by consecutive recruitment from April to November 2017. The inclusion criteria were: adults steady outpatients from 25 to 70 years old, who attend in our department of medicine, and having given their consent by signing an informed consent. The exclusion criteria were: current pregnancy and the presence of unsteady pathologies. The sample size was computed according to the proportion of cardiovascular outpatients in the department of medicine (3.96\%). By setting the precision to $5 \%$ and the $95 \%$ confidence interval (CI) to, the number of outpatient required was 292 . Demographic and clinical data: age, years, sex, smoking statute, harmful alcohol consumption, diabetes, height, weight, body mass index (BMI), waist size, hip circumference, systolic and diastolic blood pressure, diastolic blood pressure and use of hypertensive drugs were measured. Blood samples were also collected to measure total cholesterol (TC), HDL-C, low-density lipoprotein cholesterol (LDLC), TG, creatinine, uric acid, and glucose levels. The abdominal obesity index (AOI) was defined as the ratio of waist circumference to hip circumference. The average atherogenicity index (AI) was defined as the ratio of total cholesterol to HDL-cholesterol. Participants provided written informed consent and the Hospital institutional review board approved this study. Data were captured on Microsoft Excel, then imported and analyzed on Ri386 version 4.0.3. The 10-year cardiovascular risk scores were computed by using Framingham Risk Equation package and SCORE risk were calculated using an online application developed by the corresponding author. FRS equation takes into account age, sex, TC, HDLC, systolic blood pressure, smoking status, diabetes and hypotensive therapy. FRS was used to stratify patients into 3 categories of risk as follows: FRS $\leq 10 \%$ 
(low risk), $10<$ FRS $\leq 20 \%$ (intermediate risk) and FRS $>20 \%$ (high risk). The same parameters used for FRS equation calculation were used for SCORE risk equation except of HDL-C, the existence of diabetes, and ages under 45 and over 65 . The scores obtained by SCORE risk equation were also used to categorize patients, according to cardiovascular risk: SCORE $>10 \%$ (very high risk), $5 \% \leq$ SCORE $<10 \%$ ) (High risk), $1 \%<$ SCORE $<5 \%$ (moderate risk) and at the end SCORE $<1 \%$ (low risk). MetS was defined using the harmonized criteria from the International Diabetes Federation (IDF) and the American Heart Association/National Heart, Lung, and Blood Institute (AHA/NHLBI). Pearson's chisquare or Fisher's exact test was used for the comparison of proportions. The statistical significance level was set in a $\mathrm{p} \leq 0.05 \%$.

\section{Results}

A total of 292 patients was collected during this cross sectional study. The prevalence's of traditional risk factors were $14.04 \%$ of smokers, $13.01 \%$ of harmful alcohol consumption, $23.63 \%$ of MetS, $21.57 \%$ of hyperglycemia and $36.64 \%$ of high blood pressure (Figure 1). The average age of our series was $45.7 \pm 13.1$ years with the limits ranging from 25 to 70 years (Table 1). We found an average BMI of $26.1 \pm 7 \mathrm{~kg} / \mathrm{m}^{2}$. The BMI varies between 12.1 and $59.2 \mathrm{~kg} / \mathrm{m}^{2}$. The majority of our patients had a normal BMI (18.5 to 25.0$), 107$ (36.64\%). The overweight patients, BMI between 25.0 and 30.0 were 84 (28.77\%). Moderate obesity, BMI between 30.0 and 35.0 was present in 40 patients (13.70\%) while severe obesity, BMI between 35.0 and 40.0 was 15 (5.14\%). Undernutrition, BMI ( $\leq 16.5)$ was present in 14 patients (4.79\%). The thinness patients, BMI between 16.5 and 18.5 accounted for 20 patients (6.85\%) (Table 2). The AOI had an average of 0.9 and varied from 0.7 to 1.1. The mean AI was 3.9 and ranged from 1.4 to 14.0. (Table 1). The global score of the 10 -year risk was $26.3 \%$ and $8.6 \%$, according to FRS and SCORE equation, respectively. FRS equation showed that $35.62 \%$ of our

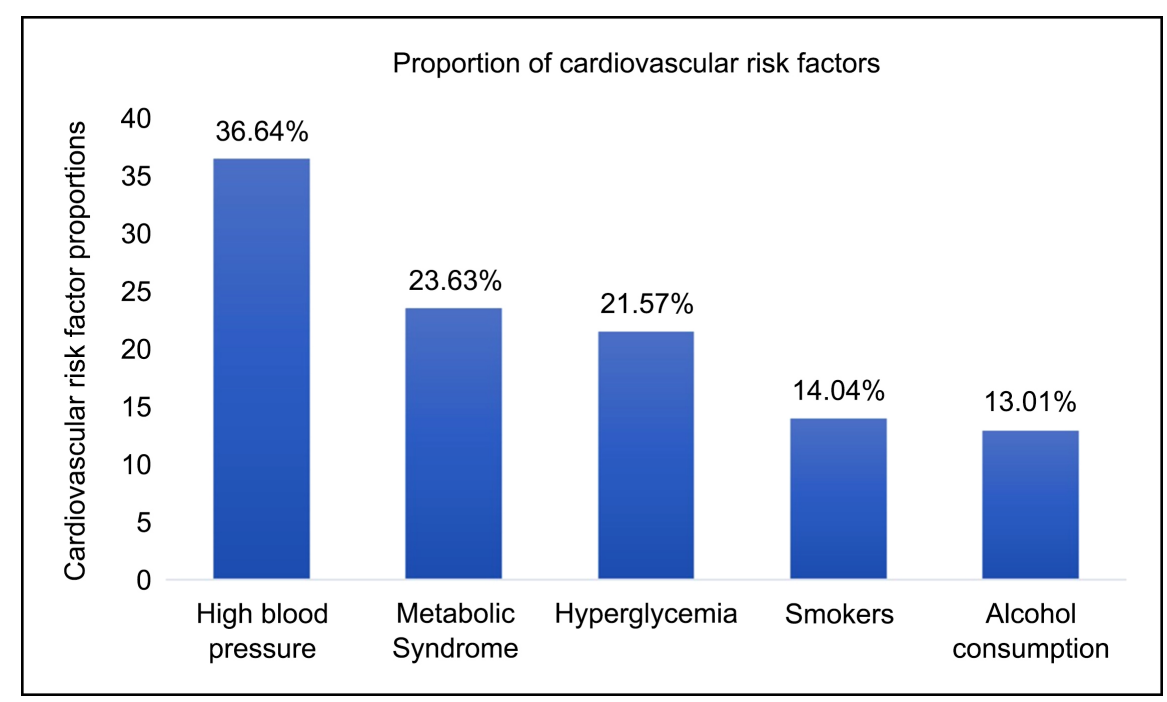

Figure 1. Proportions of cardiovascular risk factors. 
patients had a high risk, $23.29 \%$ had an intermediate risk and $41.09 \%$ had a low risk (Table 3). According to SCORE equation, $16.44 \%$ of our patient had very high risk, $19.86 \%$ had high risk, $48.63 \%$ had moderate risk and $15.07 \%$ had low risk (Table 4). The 10-year risk, according to FRS equation was significantly higher in subjects aged 50 years and above compared to subjects aged under 50, $34.46 \%$ versus $13.16 \%, \mathrm{p}<0.001$ (Figure $2(\mathrm{a})$ ). Likewise, the 10 -year risk, according to SCORE equation was also significantly higher in subjects aged 50 years and above compared to subjects under 50 years, $9.43 \%$ versus $2.09 \%, \mathrm{p}=$ 0.02 (Figure 2(b)). Regarding gender, 10-year risk FRS was significantly higher in men compared to women $49.50 \%$ versus $7.84 \%, \mathrm{p}<0.001$ (Figure $2(\mathrm{c})$ ). This same trend was observed with 10 -years risk, according to SCORE equation, $14.67 \%$ versus $4.13 \%, \mathrm{p}=0.03$ (Figure $2(\mathrm{~d})$ ).

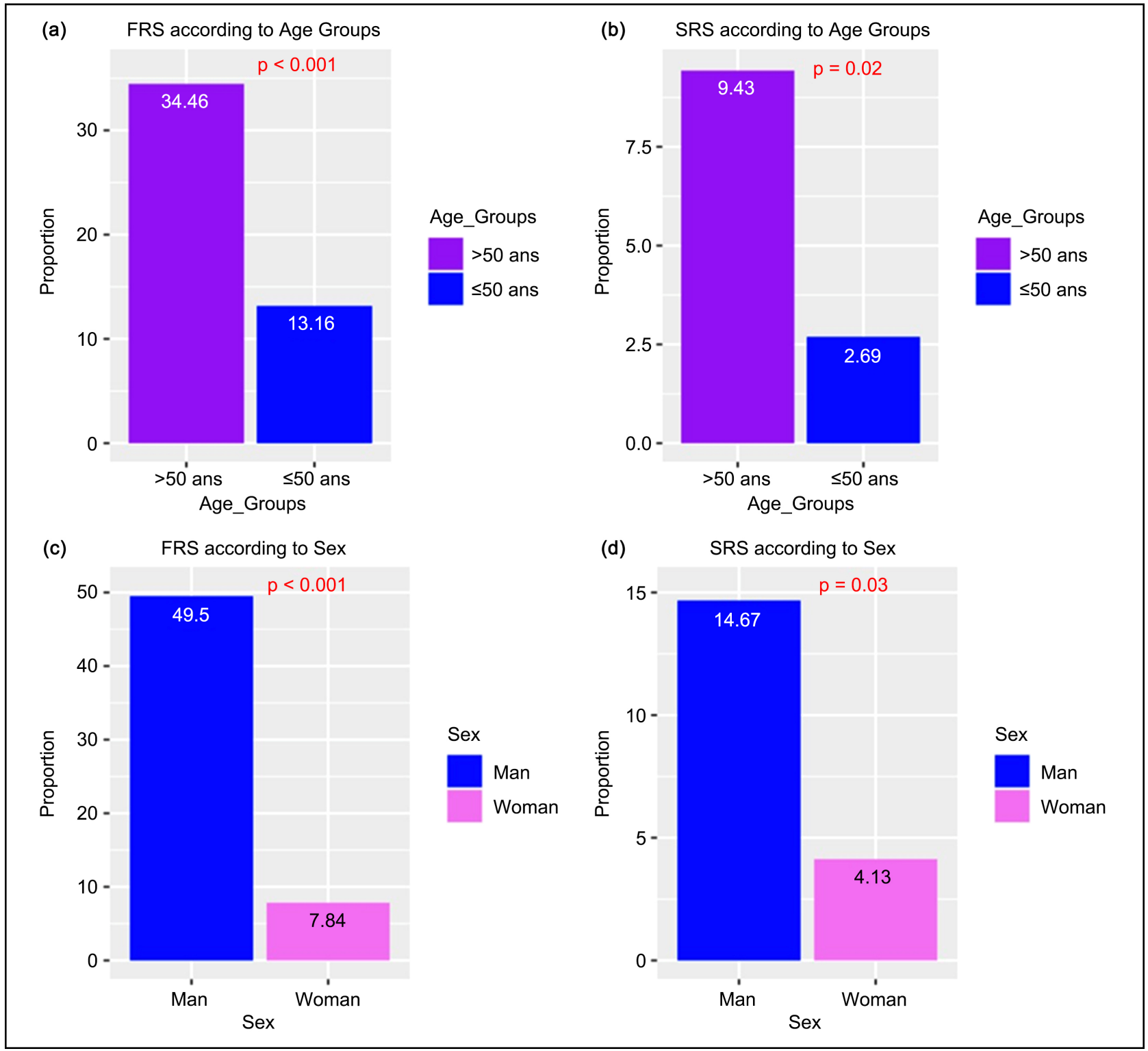

Figure 2. Proportion of Framingham Risk Score (FRS) and SCORE equations to sex and age groups. 
Table 1. Descriptive statistics of quantitative variables.

\begin{tabular}{|c|c|c|c|c|}
\hline \multirow{2}{*}{ Quantitative variables } & \multicolumn{4}{|c|}{ Descriptive statistics } \\
\hline & Minimum & Mean & SD & Maximum \\
\hline Age (years) & 25 & 45.7 & 13.1 & 70 \\
\hline Systole (mmHg) & 70 & 134 & 27.2 & 220 \\
\hline Diastole $(\mathrm{mmHg})$ & 40 & 86.8 & 17.8 & 200 \\
\hline Cardiac frequency $(\mathrm{b} / \mathrm{mm})$ & 48 & 78.4 & 18.3 & 142 \\
\hline Body mass index $\left(\mathrm{kg} / \mathrm{m}^{2}\right)$ & 12.1 & 26.1 & 7.0 & 59.2 \\
\hline Waist size $(\mathrm{cm})$ & 59 & 89.8 & 14.8 & 161 \\
\hline Hip circumference $(\mathrm{cm})$ & 65 & 100.1 & 15.0 & 165 \\
\hline Waist size/Hip circumference & 0.7 & 0.9 & 0.1 & 1.1 \\
\hline Total cholesterol (mmol/L) & 2.2 & 4.6 & 1.2 & 8.6 \\
\hline Triglycerides $(\mathrm{mmol} / \mathrm{L})$ & 0.3 & 1.2 & 0.7 & 7.1 \\
\hline HDL cholesterol $(\mathrm{mmol} / \mathrm{L})$ & 0.3 & 1.3 & 0.5 & 2.6 \\
\hline LDL cholesterol (mmol/L) & 0.3 & 2.7 & 1.1 & 6.0 \\
\hline AI (Total-C/HDL-C) & 1.4 & 3.9 & 1.7 & 14.0 \\
\hline Glucose $(\mathrm{mmol} / \mathrm{L})$ & 1.4 & 6.1 & 2.8 & 27.3 \\
\hline Creatinine $(\mu \mathrm{mol} / \mathrm{L})$ & 15.0 & 103.7 & 156.9 & 1586.8 \\
\hline Uric acid $(\mu \mathrm{mol} / \mathrm{L})$ & 59.5 & 247.6 & 120.4 & 714 \\
\hline$h s-\mathrm{CRP}(\mathrm{mg} / \mathrm{L})$ & 0.4 & 4.7 & 5.5 & 36.7 \\
\hline
\end{tabular}

Table 2. Distribution of patients, according to WHO BMI classification.

\begin{tabular}{ccc}
\hline BMI classes $\left(\mathrm{Kg} / \mathrm{m}^{2}\right)$ according to WHO & \multicolumn{2}{c}{ Body mass index classes proportions } \\
\cline { 2 - 3 } Undernutrition $(\mathrm{BMI}<16.5)$ & $\mathrm{N}$ & Percent $(\%)$ \\
Thinness $(16.5 \leq \mathrm{BMI}<18.5)$ & 14 & 4.79 \\
Reference value $(18.5 \leq \mathrm{BMI}<25.0)$ & 20 & 6.85 \\
Overweight $(25.0 \leq \mathrm{BMI}<30.0)$ & 107 & 36.64 \\
Moderate obesity $(30.0 \leq \mathrm{BMI}<35.0)$ & 84 & 28.77 \\
Severe obesity $(35.0 \leq \mathrm{BMI} \leq 40.0)$ & 40 & 5.14 \\
Massive obesity $(\mathrm{BMI}>40)$ & 15 & 4.11 \\
Total & 12 & 100 \\
\hline
\end{tabular}


Table 3. Distribution of patients, according to 10 -year risk of cardiovascular events (FRS).

\begin{tabular}{ccc}
\hline & \multicolumn{2}{c}{10 -year risk of cardiovascular events } \\
\cline { 2 - 3 } Framingham Risk Score (FRS) & $\mathrm{N}$ & Percent (\%) \\
\hline Low risk (FRS $\leq 10 \%)$ & 120 & 41.09 \\
Intermediate risk $(10<$ FRS $\leq 20 \%)$ & 68 & 23.29 \\
High risk (FRS $>20 \%)$ & 104 & 35.62 \\
Total & 292 & 100 \\
\hline
\end{tabular}

Table 4. Distribution of patients, according to 10 -year risk of cardiovascular death (SCORE).

\begin{tabular}{ccc}
\hline SCORE Risk score & \multicolumn{2}{c}{10 -year risk of cardiovascular death } \\
\cline { 2 - 3 } Low risk $($ SCORE $<1 \%)$ & $\mathrm{N}$ & Percent $(\%)$ \\
\hline Moderate risk $(1 \%<$ SCORE $<5 \%)$ & 44 & 15.07 \\
High risk $(5 \% \leq$ SCORE $<10 \%)$ & 142 & 48.63 \\
Very high risk $($ SCORE $>10 \%)$ & 58 & 19.86 \\
Total & 48 & 16.44 \\
\hline
\end{tabular}

\section{Discussion}

NCDs are the leading cause of death in the world. The majority of premature deaths, $82 \%$, occurred in low-and middle-income countries [1]. This cross-sectional study aimed to describe the cardiovascular disease risk factors among outpatients by consecutive recruitment from April to November 2017.

A total of 292 outpatients aged 25 to 70 years who attended our department of medicine were enrolled in this study. The sex-ratio was 0.66 , in over hand women were mostly represented 176/292 (60.27\%). The average age was $45.7 \pm 13.1$ years with extremes ranging from 25 to 70 years old. These data are in line with those obtained by Yehia BA, et al., 20011 [10] in the survey of the prevalence of cardiovascular disease risk factors in Tlemcen (Algeria) for a sample of 1088 subjects ( 612 women, 476 men), aged $\geq 25$ years (mean age: 42.6 years). Lemma B, et al., 2020 [11] also reported $47 \pm 11$ years as the mean of patients age and $56.4 \%$ of women in a cross-sectional survey was conducted in two referral hospitals in Eastern Ethiopia. The same trend of age median was reported by Maria F, et al., 2019 [12], however, the proportion of male sex 58.3\% in this study was in the opposite sense of our sex-ratio. Data about the median age of several cardiovascular risk assessment studies showed that the incidence of cardiovascular diseases over time has been steady or has increased in young adults [13]. The mean BMI was $26.10 \pm \mathrm{kg} / \mathrm{m}^{2}$. This result falls into the interval from 25 to 30 
$\mathrm{kg} / \mathrm{m}^{2}$ which belongs to overweight peoples. In fact, only $36.64 \%$ patient of our series had a normal BMI (18.5 to 25.0). The remainder, $51.72 \%$ were represented by subjects who were overweight or had one of the 3 forms of obesity (moderate, severe, massive). About $11.64 \%$ of our patients were thinness or undernutrition condition. Several studies reported the relationship between BMI and CVDs. In fact, in Mali, in a study of hypertension and associated factors in rural and urban areas, Hamidou OB, et al., 2018 [14] showed that the overweight and obese patients were associated with high blood pressure $\mathrm{OR}=1.54(1.04,2.27), \mathrm{OR}=2.67$ $(1.64,4.36)$, respectively. A Cameroonian series performed by Epacka E, et al., 2011 [15] also reported an average of BMI $\geq 30 \mathrm{~kg} / \mathrm{m}^{2}$. Christopher B, et al., 2015 [16] found that $10.2 \%$ of obesity during a cardiovascular risk survey in patients with chronic kidney disease attending a tertiary hospital in Uganda. In a descriptive study of the epidemiology of cardiovascular risk factors and diabetes in Sub-Saharan Africa, George AM, et al., 2013 [17] reported a rising BMI, especially in women in Southern Africa. Across the Atlantic, Peter WF, et al., 2002 [18] in a study of the determinants of cardiovascular risk (CVR) showed that high population attributable risks were related to excess weight (BMI $\geq 25)$ for the outcomes hypertension ( $26 \%$ men; $28 \%$ women), angina pectoris ( $26 \%$ men; $22 \%$ women), and coronary heart disease ( $23 \%$ men; $15 \%$ women). In the same range, Maria Fedchenko, et al., 2019 [12] found that $48.6 \%$ of adult patients with coarctation of the aorta were overweight or obese. The prevalence of smoking among our patients was $14.04 \%$. Our series had more smokers than the prevalence survey of cardiovascular risk factors in the general population in SaintLouis (Senegal) with a prevalence of $5.8 \%$ smokers reported by Pessinaba S, et al., 2013 [19]. Smoking is a well-known and modifiable risk factor for CVDs as reported by many studies [20] [21] [22] [23]. The prevalence of harmful alcohol consumption in our patients was $13.01 \%$. Hamidou OB, et al., 2018 [14] reported $2.6 \%$ of alcohol consumption exclusively represented by male sex in their series in the department of cardiology at the teaching hospital Gabriel Touré of Bamako (Mali). The high rate of harmful alcohol consumption in our series could be explained by the fact that Mopti is a crossroads that experience an unprecedented insecurity and armed conflict that could promote harmful alcohol consumption. The mean systolic and diastolic blood pressure in our series were 134.04 and $86.85 \mathrm{~mm} \mathrm{Hg}$ respectively. The prevalence of high blood pressure (HBP) was 36.64\%. Hamidou OB et al., 2018 [14] reported 137 versus $141.16 \mathrm{~mm} \mathrm{Hg}$ as the mean of systolic blood pressure (SBP) and $69.1 \%$ versus $73.1 \%$ as the prevalence of hypertension in female and male respectively. HBP was less prevalent in our series than Baldé MD, et al., 2006 [24] series who reported a prevalence of $43.6 \%$ of hypertension in an extra-hospital study at Foutah-Djallon in Guinea. Christopher B, et al., 2015 [16] in an assessment of CVR in patients with chronic kidney disease reported $90.0 \%$ of hypertension. The prevalence of hyperglycemia was $21.57 \%$ in our series. Lower prevalences were reported by Pessinaba S, et al., 2013 [19] who found 10.4\% of diabetes in Senegal; Christopher B, et al., 2015 
[16] reported $16.1 \%$ in their series while Chandrasekhar D, et al., 2015 [25] reported $51.0 \%$ diabetic in a population presenting an acute coronary syndrome. Baldé MD, et al., 2006 [24] found a significant difference in the prevalence of diabetes among hypertensive subjects and subject in normotension $5.9 \%$ versus 9.65, $\mathrm{p}<0.001$. The global 10-year risk of cardiovascular events (fatal or nonfatal coronary artery disease, stroke, peripheral vascular disease, chronic heart failure and heart death) or cardiovascular death was $26.33 \%$ and $8.57 \%$ according to FRS and SCORE, respectively. Pessinaba S, et al., 2013 [19] in Senegal in a cross-sectional study in subjects aged 15 years and older reported an overall cardiovascular risk of $24.9 \%$ according to the FRS and $6.1 \%$ according to the SCORE model. The difference in 10-years FRS score between Pessinaba S, et al., and our series could be explained by the lower limit of age that was 25 years in our series versus 15 years for Pessinaba S. The distribution of our patients, according to the FRS showed that $35.62 \%$ were at high risk (FRS $>20 \%$ ). Patients at intermediate risk $(10 \%<\mathrm{FRS} \leq 20 \%)$ represented $23.29 \%$ and patients at low risk (FRS $\leq 10 \%$ ) were $41.09 \%$. Naveen G, et al., 2017 [26] in a study on the comparison of different cardiovascular risk score calculators for cardiovascular risk prediction and guideline recommended statin uses, showed that FRS-CVD risk assessment model has performed the best as it could identify the highest number of patients (51.9\%) to be at high CVD risk while WHO and atherosclerotic cardiovascular disease (ASCVD) calculators have performed the worst (only $16.2 \%$ and $28.3 \%$ respectively were stratified into high CVD risk) considering $20 \%$ as cut off for high risk definition. According to the 10-year SCORE assessment, the distribution of our patients was as follows: patients at very high risk were $16.44 \%$, patients at high risk were $19.86 \%$, patients at moderate risk were $48.63 \%$ and patients at low risk were $15.07 \%$. Heleniak Z et al., 2018 [27] in an assessment of cardiovascular risk in renal transplant recipients showed that high and very high risk of cardiovascular endpoint according FRS and SCORE scales was found in $10 \%$, and $41 \%$ of patients, respectively. After 5 years of follow-up, the prevalence of patients at high and very high risk, according to FRS and SCORE reached $18 \%$, and $45 \%$, respectively. A low prevalence of patients at very high 10-years risk was reported by José LRA et al., 2014 [28] in a cardiovascular risk assessment according to a national calibrated score, risk index in psoriatic arthritis patients without clinically evident cardiovascular disease or classic atherosclerosis risk factors $11 \%$. The risk scores must be interpreted according to the population and the clinical setting because of the disparity between geographical areas. Because of the discrepancies of FRS, SCORE algorithm was developed in Europe to take into account geographic disparities. SCORE does not assess the overall 10-year risk of coronary events like Framingham but the 10-year risk of cardiovascular death. SCORE algorithm takes into account the same risk factors as Framingham (except HDL-C level, existence of diabetes and ages under 45 and over 65 years) [4] [5]. Moreover, beyond traditional CVDs 10 -years risk assessment tools, there are new imaging technology and biomark- 
ers that could significantly improve discriminatory value of FRS and SCORE by providing cardiovascular risk reclassification or informed therapeutic policies. Among these, we can cite the coronary artery calcium (CAC) Udo H, et al., 2016 [29], Congying X et al., 2020 [30], the deep "omics" studies, Charlotte A et al., 2019 [31] and the high sensitivity-C-reactive protein (hs-CRP) Peter WF et al., 2008 [32] and José LRA et al., 2014 [28]. According to the sex, the 10-year risk scores were significantly higher in men than women, $49.54 \%$ versus $7.84 \%, \mathrm{p}<$ 0.001 and $14.67 \%$ versus $4.13 \% \mathrm{p}=0.03$ for FRS and SCORE, respectively. Our results are in line with Eleazar E, et al., 2020 [23] who reported that patients at FRS high risk account for $46 \%$ versus $15 \%$ and at SCORE high risk were $32.4 \%$ versus $11.8 \%$ for men and women, respectively. In contrast, Karice K Hyun, et al., 2019 [33] in a meta-analysis study reported that the CVD risk score and risk factors were similar in women and men and the pooled, adjusted likelihood of having the risk score were comparable between women and men: OR (95\% CI): $0.87(0.70,1.07) ; 1.41(0.89,2.25)$; and $1.15(0.82,1.60)$, respectively. The debate on the differences between men and women in terms of cardiovascular risk prediction still drives ongoing research. Some authors have reported that women under the age of 50 years were less likely to experience myocardial infarction compared to men of the same age, but after menopause, the incidence in women reach almost the same proportion of men, suggesting that estrogen could play a cardioprotective role but results from randomized clinical trials challenge this hypothesis according to Gretchen LW et al., 2016 [34]. The 10-year risk scores increased with age in our series. In fact, we found significant differences between subjects aged 50 years and above compared to those under 50 years, $34.46 \%$ versus $13.16 \%, \mathrm{p}<0.001$ and $9.43 \%$ versus $2.69 \%, \mathrm{p}=0.02$ for FRS and SCORE, respectively. These results are in line with those obtained by the Framingham and MONICA studies, which showed that the risk of coronary heart disease increased markedly with age Charlotte A et al., 2019 [31], Gostynski M, et al., 2004 [35]. Grzegorz G, et al., 2020 [22] reported that in the subgroup aged 50 years and above, high and very high cardiovascular risk scores were observed in almost one-third of Polish soldiers and moderate or high risk score was found in younger subgroups.

One of the limitations of this study is the lack of cardiovascular risk assessment tool adapted to the Sub Saharan African population. It is known that Framingham risk score and SCORE risk developed for American et European populations do not express cardiovascular risk in the same pattern when used in other populations [36] [37] [38]. The second is that our data are intra-hospital, it will be interesting to perform a comprehensive assessment of NCDs at the community level. The third is that although our work take into account crosssectional data in analyses, it did not tease apart the relative impact of the baseline of risk factor in predicting future CVD risk in a longitudinal study like Framingham heart study and SCORE study. So there is a need for longitudinal studies in Sub Saharan African in order to develop informed policies adapted to the 
geographic and behavioral disparities, linked to this population as coined by previous authors [31] [36]. Moreover, in 2007 the WHO and the International Society of Hypertension (ISH) published the WHO/ISH CVD risk charts for all WHO epidemiological sub-regions of the world. These charts are to be used as part of the WHO's Package of Essential NCD (PEN) Interventions for Primary Health Care in Low-Resource Settings in jurisdictions that do not have their own population-derived risk assessment algorithms [39]. However, our study could help the comparison between different populations or could help the calibration of assessment tools.

Community-level assessment of cardiovascular risk factors and the longitudinal studies are needed for a better understanding of the epidemiology of cardiovascular risk factors in order to refine informed prevention and therapeutic policies.

\section{Conclusion}

Our data corroborate the increasing prevalence of cardiovascular risk factors in SSA. A comprehensive cardiovascular risk factor assessment should be implemented in all stages of health facilities and a longitudinal follow-up could help shed a light on the epidemiology of NCDs in general and particularly CVDs and thereby improve their control policies in SSA.

\section{Acknowledgements}

We are grateful to all study subjects for participating in this study; the staff of Mopti Hospital, Mopti, Mali, Faculty of Pharmacy, Bamako, Mali for their assistance.

\section{Statement of Informed Consent}

Each participant gave fully informed written consent prior to enrollment. The protocol was reviewed and approved by the Mopti hospital scientific committee.

\section{Disclosure of Conflict of Interest}

The authors certify that there is no actual or potential conflict of interest in relation to this article.

\section{References}

[1] World Health Organization (2018) Noncommunicable Diseases Country Profiles. https://www.who.int/nmh/publications/ncd-profiles-2018/en

[2] Jahangiry, L., Farhangi, M.A. and Rezaei (2017) Framingham Risk Score for Estimation of 10 Years of Cardiovascular Diseases Risk in Patients with Metabolic Syndrome. Journal of Health, Population and Nutrition, 36, 36. https://doi.org/10.1186/s41043-017-0114-0

[3] Dennis, T.K., Atul, S., Maneesh, S., Gynter, K., Paymon, A., Maria, K., Peter, C.A., et al. (2020) Calibration and Discrimination of the Framingham Risk Score and the Pooled Cohort Equations. CMAJ, 192, 442-449. 
https://doi.org/10.1503/cmaj.190848

[4] Vitali, G. and Anja, H. (2015) Overview of Risk-Estimation Tools for Primary Prevention of Cardiovascular Diseases in European Populations. Central European Journal of Public Health, 23, 91-99. https://doi.org/10.21101/cejph.a4004

[5] Marco, P., Jessica, L.R., Dörte, H., Nina, M., Natalie, E., Giancarlo, L., Elke, S., et al. (2020) Performance of Risk Prediction Scores for Cardiovascular Mortality in Older Persons: External Validation of the Score OP and Appraisal. PLOS ONE, 15, e0231097. https://doi.org/10.1371/journal.pone.0231097

[6] Alberti, K.G. and Zimmet, P.Z. (1998) Definition, Diagnosis and Classification of Diabetes Mellitus and Its Complications, Part 1: Diagnosis and Classification of Diabetes Mellitus Provisional Report of a WHO Consultation. Diabetic Medicine, 15, 539-553. https://doi.org/10.1002/(SICI)1096-9136(199807)15:7<539::AID-DIA668>3.0.CO;2-S

[7] National Cholesterol Education Program (NCEP) Expert Panel on Detection, Evaluation, and Treatment of High Blood Cholesterol in Adults (Adult Treatment Panel III) (2002) Third Report of the National Cholesterol Education Program (NCEP) Expert Panel on Detection, Evaluation, and Treatment of High Blood Cholesterol in Adults (Adult Treatment Panel III) Final Report. Circulation, 106, 3143-3421.

https://pubmed.ncbi.nlm.nih.gov/12485966

https://doi.org/10.1161/circ.106.25.3143

[8] Alberti, K.G., Zimmet, P., Shaw, J. and IDF Epidemiology Task Force Consensus Group (2005) The Metabolic Syndrome: A New Worldwide Definition. The Lancet, 366, 1059-1062. https://doi.org/10.1016/S0140-6736(05)67402-8

[9] Alberti, K.G., Robert, H.E., Scott, M.G., Paul, Z.Z., James, I.C., Karen, A.D., Jean, C.F., et al. (2009) Harmonizing the Metabolic Syndrome: A Joint Interim Statement of the International Diabetes Federation Task Force on Epidemiology and Prevention; National Heart, Lung, and Blood Institute; American Heart Association; World Heart Federation; International Atherosclerosis Society; and International Association for the Study of Obesity. Circulation, 120, 1640-1645. https://doi.org/10.1161/CIRCULATIONAHA.109.192644

[10] Yahia, B.A., Benyoucef, M., Meguenni, K. and Brouri, M. (2011) Survey on the Prevalence of Risk Factors for Cardiovascular Diseases at Tlemcen (Algérie). Médecine des Maladies Métaboliques, 5, 42-48. https://doi.org/10.1016/S1957-2557(11)70071-2

[11] Lemma, B.N., Judy, M., Philippa, R. and Jeroen, M.L. (2020) Patients' Knowledge on Cardiovascular Risk Factors and Associated Lifestyle Behaviour in Ethiopia in 2018: A Cross-Sectional Study. PLoS ONE, 15, e0234198.

https://doi.org/10.1371/journal.pone.0234198

[12] Maria, F., Zacharias, M., Helena, D., Görel, H.O., Anna, B., Peter, E. and Mikael, D. (2019) Cardiovascular Risk Factors in Adults with Coarctation of the Aorta. Congenital Heart Disease, 14, 549-558. https://doi.org/10.1111/chd.12785

[13] Charlotte, A. and Ramachandran, S.V. (2018) Epidemiology of Cardiovascular Disease in Young Individuals. Nature Reviews Cardiology, 15, 230-240.

https://doi.org/10.1038/nrcardio.2017.154

[14] Hamidou, O.Bâ., Youssouf, C., Ichaka, M., Ibrahima, S., Noumou, S., Diall, I.B., Souleymane, C., et al. (2018) Hypertension and Associated Factors in Rural and Urban Areas Mali: Data from the STEP 2013 Survey. International Journal of Hypertension. https://doi.org/10.1155/2018/6959165

[15] Epacka, E.S.M., Mandengue, H., Ahmadou, G., Moumbe, T.S., Dzudie, A. and Lu- 
ma, N.H. (2011) Screening for Cardiovascular Diseases and Risk Factors in a Cohort of 270 Cameroon Inhabitants: Effect of Physical and Sport Activities. Médecine des Maladies Métaboliques, 5, 655-658. https://doi.org/10.1016/S1957-2557(11)70342-X

[16] Christopher, B., Robert, K., Emmy, O., Barbara, K., Elias, S., Michael, M. and Charles, K.M. (2015) Cardiovascular Risk Factors among Patients with Chronic Kidney Disease Attending a Tertiary Hospital in Uganda. Cardiovascular Journal of Africa, 26, 177-180. https://doi.org/10.5830/CVJA-2015-045

[17] George, A.M. (2013) Descriptive Epidemiology of Cardiovascular Risk Factors and Diabetes in Sub-Saharan Africa. Progress in Cardiovascular Diseases, 56, 240-250. https://doi.org/10.1016/j.pcad.2013.10.014

[18] Peter, W.F.W., Ralph, B.D., Lisa, S., Helen, P. and William, B.K. (2002) Overweight and Obesity as Determinants of Cardiovascular Risk the Framingham Experience. Archives of Internal Medicine, 162, 1867-1872. https://doi.org/10.1001/archinte.162.16.1867

[19] Pessinaba, S., Mbaye, A., Yabéta, G.A., Harouna, H., Sib, A.E., Kane, A.D., Bodian, M., et al. (2013) Prevalence Survey of Cardiovascular Risk Factors in the General Population in St. Louis (Senegal). Annales de Cardiologie et d Angéiologie, 62, 253-258. https://doi.org/10.1016/j.ancard.2013.02.005

[20] Wouter, C.M. and Rudolf, A.B. (2019) Common Risk Factors for Heart Failure and Cancer. Cardiovascular Research, 115, 844-853. https://doi.org/10.1093/cvr/cvz035

[21] Turgay, S., Sebastian, D.R., Jennifer, N., Jonas, S., Matthias, S., Mohamed, M., Stephan, A., et al. (2019) Epicardial Fat, Cardiovascular Risk Factors and Calcifications in Patients with Chronic Kidney Disease. Clinical Kidney Journal, 13, 571-579. https://doi.org/10.1093/ckj/sfz030

[22] Grzegorz, G., Paweł, K., Katarzyna, P., Piotr, M., Andrzej, S., Adam, S., Agata, G., et al. (2020) The Prevalence of Cardiovascular Risk Factors among Polish Soldiers: The Results from the MIL-SCORE Program. Cardiology Research and Practice, 2020, Article ID: 3973526. https://doi.org/10.1155/2020/3973526

[23] Eleazar, E.M.S., Samuel, A.U., Aida, A.R., Gabriela, D., Axel, M., Ricardo, R., et al. (2020) Cardiovascular Risk Assessment in the Resource Limited Setting of Western Honduras: An Epidemiological Perspective. IJC Heart \& Vasculature, 27, Article ID: 100476. https://doi.org/10.1016/j.ijcha.2020.100476

[24] Baldé, M.D., Baldé, N.M., Kaba, M.L., Diallo, I., Diallo, N.M., Kake, A., Bah, D., et al. (2006) Arterial Hypertension: Epidemiology and Metabolic Abnormalities in Foutah-Djallon (Guinea). Mali Medical, 21, 19-22.

https://pubmed.ncbi.nlm.nih.gov/19435002

[25] Chandrasekhar, D., Shinu, C., Molniya, B. and Danisha, P. (2015) Prevalence of Cardiovascular Risk Factors and Management Practices of Acute Coronary Syndrome in a Tertiary Care Hospital. Journal of Basic and Clinical Physiology and Pharmacology, 6, 547-554.

[26] Naveen, G., Subrat, K.M., Aditya, K., Satyendra, T., Sudeep, K., Roopali, K. and Pravin, K.G. (2017) Comparison of Different Cardiovascular Risk Score Calculators for Cardiovascular Risk Prediction and Guideline Recommended Statin Uses. Indian Heart Journal, 69, 458-463. https://doi.org/10.1016/j.ihj.2017.01.015

[27] Heleniak, Z., Komorowska, J.K. and Dębska, Ś.A. (2018) Assessment of Cardiovascular Risk in Renal Transplant Recipients: Preliminary Results. Transplantation Proceedings, 50, 1813-1817. https://doi.org/10.1016/j.transproceed.2018.03.127

[28] José, L.R.A., Jesús, C.H., Juan, S., César, M.C., Miguel, Á.G.G. and Enrique, R.Á. (2014) Cardiovascular Risk Assessment According to a National Calibrated Score 
Risk Index in Psoriatic Arthritis Patients without Clinically Evident Cardiovascular Disease or Classic Atherosclerosis Risk Factors. Joint Bone Spine, 81, 164-168. https://doi.org/10.1016/j.jbspin.2013.07.008

[29] Udo, H., Joseph, M.M., Ralph, B.D.S., Sekar, K., Caroline, S.F. and Christopher, J.O. (2016) Cardiovascular Event Prediction and Risk Reclassification by Coronary, Aortic, and Valvular Calcification in the Framingham Heart Study. Journal of the American Heart Association, 5, e003144. https://doi.org/10.1161/JAHA.115.003144

[30] Congying, X., Marleen, V., Grigory, S., Martijn, D.D., Matthijs, O., Jurjen, N.V.B., Gert, J.P., et al. (2020) Cardiovascular Risk Factors and Coronary Calcification in a Middle-Aged Dutch Population: The ImaLife Study. Journal of Thoracic Imaging, $1-7$.

[31] Charlotte, A., Andrew, D.J., Emelia, J.B., Daniel, L. and Ramachandran, S.V. (2019) 70-Year Legacy of the Framingham Heart Study. Nature Reviews Cardiology, 16, 687-698. https://doi.org/10.1038/s41569-019-0202-5

[32] Peter, W.F., Wilson, M.P., Paul, J., Jacob, S., Ralph, D.S. and Christopher, J.O. (2008) C-Reactive Protein and Reclassification of Cardiovascular Risk in the Framingham Heart Study. Circulation: Cardiovascular Quality and Outcomes, 1, 92-97. https://doi.org/10.1161/CIRCOUTCOMES.108.831198

[33] Karice, K.H., Elizabeth, R.C.M., Julie, R., David, B., Sanne, A.E.P. and Mark, W. (2019) Sex Differences in the Assessment of Cardiovascular Risk in Primary Health Care: A Systematic Review. Heart, Lung and Circulation, 28, 1535-1548. https://doi.org/10.1016/j.hlc.2019.04.005

[34] Gretchen, L.W. (2016) Cardiovascular Risk Factors: Does Sex Matter? Current Vascular Pharmacology, 14, 452-457. https://doi.org/10.2174/1570161114666160722113116

[35] Gostynski, M., Gutzwiller, F., Kuulasmaa, K., Döring, A., Ferrario, M., Grafnetter, D., Pajak, A., et al. (2004) Analysis of the Relationship between Total Cholesterol, Age, Body Massindex among Males and Females in the Monica Project. International Journal of Obesity and Related Metabolic Disorders, 28, 1082-1090. https://doi.org/10.1038/sj.ijo.0802714

[36] Daniel, B., Charles, A., Erik, B., Karlijn, M., Liam, S., Matthias, B.S., Juliet, A., et al. (2018) Cardiovascular Disease Risk Prediction in Sub-Saharan African Populations-Comparative Analysis of Risk Algorithms in the RODAM Study. International Journal of Cardiology, 254, 310-315. https://doi.org/10.1016/j.ijcard.2017.11.082

[37] Mosepele, M., Linda, C.H., Tommy, P., Isaac, N., Kara, B., Shahin, L. and Virginia, A.T. (2017) Cardiovascular Disease Risk Prediction by the American College of Cardiology (ACC)/American Heart Association (AHA) Atherosclerotic Cardiovascular Disease (ASCVD) Risk Score among HIV-Infected Patients in Sub-Saharan Africa. PLoS ONE, 12, e0172897. https://doi.org/10.1371/journal.pone.0172897

[38] Klug, E., Raal, F.J., Marais, A.D., Smuts, C.M., Schamroth, C., Jankelow, D., Blom, D.J., et al. (2018) South African Dyslipidaemia Guideline Consensus Statement: 2018 Update A Joint Statement from the South African Heart Association (SA Heart) and the Lipid and Atherosclerosis Society of Southern Africa (LASSA). South African Medical Journal, 108, 973-1000. https://pubmed.ncbi.nlm.nih.gov/30421699

[39] Mendis, S., Lindholm, L.H., Mancia, G., et al. (2007) World Health Organization and International Society of Hypertension Risk Prediction Charts: Assessment of Cardiovascular Risk for Prevention and Control of Cardiovascular Disease in Low and Middle-Income Countries. Journal of Hypertension, 25, 1578-1582. https://doi.org/10.1097/HJH.0b013e3282861fd3 